\title{
Building Regional Capacities for GEOSS and INSPIRE: a Journey in the Black SeaCatchment
}

\author{
Gregory Giuliani, Nicolas Ray, Anthony Lehmann \\ Institute for Environmental Sciences, enviroSPACE \\ University of Geneva \\ 1227 Carouge, Switzerland \\ gregory.giuliani@unige.ch
}

\author{
Gregory Giuliani, Nicolas Ray \\ United Nations Environment Programme \\ Global Resource Information Database \\ 1211 Châtelaine, Switzerland
}

\begin{abstract}
To understand environmental systems like the Black Sea catchment, it is required to gather and integrate different datasets. However, data discoverability, accessibility and integration are among the most frequent difficulties that scientists are regularly facing. To tackle these issues, capacity building (at human, institutional, and technical levels) is recognized as a key enabler to raise awareness and create commitments on the benefits of data sharing and publication using interoperable services. In this paper, we present experiences and lessons learnt in the frame of the EU FP7 project enviroGRIDS in developing a network of GEO partners and an efficient strategy to build capacities of scientists from different countries in the Black Sea region. As a result, 27 services, providing access to more than 300 (local or regional) environmental datasets corresponding to around 300'000 layers, are currently registered into the Global Earth Observation System of Systems (GEOSS). Finally, we discuss the added value for stakeholders in the region to participate into GEOSS and the European directive on data sharing INSPIRE, and how to improve its visibility and credibility in the research community, among potential end users.
\end{abstract}

Keywords-enviroGRIDS; Capacity Building; GEOSS; Black Sea; Spatial Data Infrastrcuture; Grid computing

\section{INTRODUCTION}

The Black Sea catchment is a particularly interesting and complex region that is under several environmental pressures from global changes (e.g. climate, demography, land cover) that are influenced by its geophysical and geopolitical situation [1]. First, the Black Sea is almost a closed sea, with reduced exchanges with the Mediterranean Sea through the Bosporus, which led to anoxic conditions in deeper water layers. Second, the Black Sea catchment is very large, covering 2.2 million $\mathrm{km}^{2}$ and draining more than 150 million inhabitants. Third, by joining the European Union, Bulgaria and Romania brought back the Black Sea on the shores of Europe. Forth, the main tributaries (e.g., Danube, Dnieper, Dniester, Don, Rioni, Kizilirmak) drain large agricultural regions and pass trough numerous dams that both modify significantly the water and sediment quantity and quality reaching the Black Sea. These issues are of particular interest for two important environmental regional commissions, namely the Commission on the Protection of the Black Sea Against Pollution $\left(\mathrm{BSC}^{1}\right)$ and the International Commission for the Protection of the Danube

1 http://www.blacksea-commission.org
River $\left(\mathrm{ICPDR}^{2}\right.$ ). The main challenge for the BSC is to fix targets to reduce nutrient loads into the Black Sea from the different catchments/countries. For the ICPDR, the efforts made under the European Water Framework Directive to improve the condition of the Danube river need to have some impacts in the Black Sea as well. The know-how of the ICPDR could be very beneficial to the rest of the catchment to improve the implementation of integrated water resource management in transboundary catchments.

The enviroGRIDS project has explored several scenarios of development for the future of this region [2] with the aim to provide the key spatially explicit information on the past, the present and the future to set the scene for improved decision making. In order to respond to some of the questions related to the water societal benefit areas as defined by the Group on Earth Observations $\left(\mathrm{GEO}^{3)}\right.$, the enviroGRIDS project developed for the first time a full catchment hydrological model to predict water quality and quantity according to these different scenarios. To reach its objectives, enviroGRIDS needed to gather, share and process a huge amount of Earth Observation data. In collaboration with other related European projects such as PEGASO ${ }^{3}$, BlackSeaScene ${ }^{4}$, OBSERVE $^{5}$, BalkanGEONet ${ }^{6}$, IASON ${ }^{7}$, EOPOWER $^{8}$, enviroGRIDS is bringing a completely new solution to explore the environment of the Black Sea catchment.

One of the challenges authorities are facing worldwide is the coordination and effective use of the vast amount of geospatial data that is generated continuously [3, 4]. The majority of these data is stored in "electronic silos" at different locations, managed by different organizations [5]. Often, available data are only partly accessible and if they are, often incompatible with one another because of different data formats and standards, data policy, protocols of measurement or analysis, different geographical projection, spatial resolution, lateral overlaps or gaps. Inevitably this can lead to

\footnotetext{
2 http://www.icpdr.org

3 http://www.pegasoproject.eu

4 http://www.blackseascene.net

5 http://www.observe-fp7.eu

6

http://www.balkangeo.net

7 http://iason-fp7.eu

8 http://www.eopower.eu
} 
inefficiencies and duplication efforts. Moreover the increasing resolution and volume of data require more and more computing resources [6] and consequently limit the possibilities to use them in complex analysis workflow on single desktop computers.

To improve the capacity of scientists to assess the sustainability and vulnerability of the environment and to provide understandable and usable information to decision makers, an essential prerequisite is to convince and help regional data holders to make available their data and metadata to a larger audience in order to facilitate data discovery, access, and analysis.

To address the need of improved environmental data sharing and processing, an interdisciplinary approach can be appropriate. Indeed, Spatial Data Infrastructure (SDI) concept propose a framework to encompass data sources, systems, network linkages, standards and institutional issues in delivering geospatial data and information from many different sources to the widest possible group of potential users [7]. To enable efficient and effective data publication, discovery, evaluation, and access, SDIs mostly rely on interoperability, the capacity to exchange data between two or more systems and to use it. The Open Geospatial Consortium $\left(\mathrm{OGC}^{9}\right)$ is an international voluntary consensus standards organization that promotes and develops open standards for geospatial data and information [8-13]. However, currently SDIs are lacking of computational resources to process the vast amount of data [14]. Therefore, distributed computing paradigm can offer capabilities to complement SDIs. OGC standards can enable an efficient and scalable solution to link these two heterogeneous technologies. This leverages wide and effective exchanges of data, maximizing the value and reuse of data. The capacity to exchange with other systems may also enable new knowledge to emerge from relationships that were not anticipated previously.

Several initiatives at the regional and global scales are promoting the creation of SDIs. These initiatives coordinate actions to promote awareness and implementation of policies, common standards and effective mechanisms for the development and availability of interoperable geospatial data and technologies to support decision making at all levels and for various purposes [15]. At the European level, The Infrastructure for Spatial Information in the European Community (INSPIRE ${ }^{10}$ ) is a legal directive that is aiming to enable sharing of environmental information to support formulation, implementation, monitoring and evaluation of European policies [16]. At the global scale, the Global Earth Observation System of Systems (GEOSS) is a voluntary effort coordinated by the Group on Earth Observation (GEO) to connect existing SDIs and Earth Observation infrastructures and to act as a gateway between data producers and users [17]. The primary objective is to enhance the relevance of Earth observations for the global problems and to offer public access to comprehensive information and analyses on the environment. To support the nine defined Societal Benefit

\footnotetext{
9 http://www.opengeospatial.org

10 http://inspire.jrc.ec.europa.eu
}

Areas (SBAs) on disasters, health, energy, climate, water, weather, ecosystems, agriculture, biodiversity, data sharing principles and interoperability arrangements are presented in a 10-year Implementation Plan Reference Document [18] that any participant must endorse.

To reach large adoption, acceptation and commitment on data sharing principles and to increase ability to access and use Earth Observations (EOs) and environmental data, GEO has developed a Capacity Building (CB) Strategy [19]. GEO's definition is based on the one provided by the United Nations Conference on Environment and Development (UNCED) encompassing "human, scientific, technological, organizational and institutional resources and capabilities" to "enhance the abilities of stakeholders to evaluate and address crucial questions related to policy choices and different options for development" [19]. Three levels are of particular relevance for GEO:

- Human: education and training of people to be aware of and able to access, use, and develop EO data and services.

- Institutional: development of a working environment (e.g., data policies, organizational and decision structures) for the use of EO to enhance decisionmaking.

- Infrastructure: hardware, software and technology needed to access, use and develop EO services for decision-making.

Particular attention must be devoted to demonstrate the benefits of sharing data through appropriate examples, best practices and guidelines. This helps to strengthen (1) existing observation systems, (2) capacities of decision-makers to use it, and (3) capacities of the general public to understand important environmental, social and economical issues at stake in the region. Additionally, capacity building efforts should aim at convincing a maximum of data owners/providers that they have an opportunity to become more visible nationally and internationally by joining the effort of GEOSS [20].

GEO's survey has revealed several issues related to capacity building, particularly in developing countries [19]:

- Limited access to CB resources;

- Lack of e-science infrastructure for EO education and training;

- Need for criteria and standards for EO CB,;

- Gaps between EO research and operational application;

- Inefficient connectivity between providers and users of EO systems;

- Need for cooperation within and between developed and developing countries and regions;

- Lack of awareness about the value of EO among decision makers; and

- Duplication of EO CB efforts. 
Consequently, there are many opportunities to improve this situation [21-23]. GEO is seeking to coordinate and build synergies upon existing efforts and best practices to enhance efficient use of $\mathrm{CB}$ resources by:

1) responding and focusing to users needs;

2) fostering collaboration and partnership;

3) concentrating on end-to-end EO needs;

4) enhancing the sustainability of existing and future EO capacity building efforts by raising awareness amongst decision makers, and

5) facilitating the development of comprehensive, sustainable CB efforts to address the needs for infrastructure, education and training, and to build local institutional capacity.

GEO has a dedicated committee on Capacity Building ${ }^{11}$ to support the countries to use and benefits from EO products and services and to contribute to GEOSS. There is also a Capacity Building section on the GEO portal, the entry point to discover content in GEOSS, and to access capacity building resources ${ }^{12}$. In complement, there is also a Best Practices Wiki maintained by IEEE to compile and review best practices in all fields of $\mathrm{EO}^{13}$. Finally the task ID-02 "Developing Institutional and Individual Capacity" of the GEO workplan is seeking to promote and coordinate actions related to capacity building in GEOSS like the Architecture Implementation Pilots (AIP) activities, the Data Sharing Principles implementation, or the contributions from EU FP7 projects.

Recognizing these opportunities, enviroGRIDS built the capacity of scientists to publish data on the Black Sea catchment using OGC standards, the capacity of decisionmakers to use them, and the capacity of the general public to understand the important environmental, social and economic issues in the region. The main objective remains bridging the gap between science and policy by targeting the needs of the Black Sea Commission (BSC) and the International Commission for the Protection of the Danube River (ICPDR). Based on these considerations the aim of this paper is to explore (1) Why does the Black Sea catchment need EO?, (2) Is the Black Sea region ready for $\mathrm{EO}$ at the human, institutional and infrastructure levels?, and (3) What is still needed to further improve these capacities?

\section{GAP ANALYSIS IN THE BLACK SEA CATCHMENT}

To better understand the status of EO in the Black Sea Catchment region a gap analysis was carried out during the first two years of the project (1) to identify the list of existing datasets and observation systems (OS) within the Black Sea catchment, (2) to assess their level of compatibility with the international standards of interoperability, and (3) to identify areas where further efforts are needed to reinforce existing observation systems in this region.

\footnotetext{
11 http://www.earthobservations.org/ag_cbc.shtml

12 http://www.geoportal.org/web/guest/geo_capacitybuilding

$13 \mathrm{http} / / /$ wiki.ieee-earth.org
}

To gather this information an online questionnaire was developed and sent to all project partners, who were requested to provide information about used and available data, observation systems and information networks within their areas of activity from local, national, regional, and global scales. In addition, they were also requested to provide lists of end-users and data needs. To complement the information provided by project partners an intensive Internet search for available data and OS was performed. In total, information about 162 datasets and 30 observations systems covering the Black Sea catchment were identified. The analysis of the identified datasets and observation systems against the project requirements revealed spatial and temporal gaps in data coverage, gaps in observation systems, problems with data accessibility, compatibility and interoperability.

The datasets reported by project partners' cover all 9 GEOSS Societal Benefits Areas (SBAs). The initial statistic of relevance of the reported datasets to SBAs is presented in Table 1. The GEOSS SBAs in this table are sorted according to their relevance frequency. Statistic shows that most of the datasets are related to the Water, Ecosystems, and Climate SBAs, while least covered SBAs are Energy, Weather and Health SBAs. Considering the importance of weather data to build the SWAT hydrological model [24], the limited amount of data for this SBA was an important gap.

TABLE I. RELEVANCE OF PARTNER'S DATASETS TO GEOSS SBAS

\begin{tabular}{|c|c|c|c|c|c|c|c|c|c|}
\hline \multirow[b]{2}{*}{ Datasets } & \multicolumn{9}{|c|}{ GEOSS SBAS } \\
\hline & 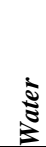 & 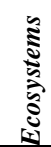 & 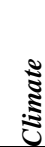 & 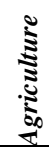 & 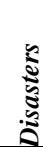 & 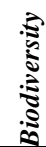 & 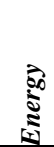 & ڤั & $\frac{\pi}{3}$ \\
\hline $\begin{array}{l}\text { Collected / } \\
\text { operated by } \\
\text { partners }\end{array}$ & 61 & 57 & 50 & 50 & 47 & 41 & 33 & 21 & 21 \\
\hline Used by partners & 15 & 13 & 12 & 10 & 8 & 10 & 7 & 3 & 6 \\
\hline
\end{tabular}

Even if large amount of data sets relevant for the project and end-users was available at different scales (e.g., national, regional, global), data access was often limited or restricted, particularly at the national level. Project partners reported national datasets only for four countries: Georgia, Hungary, Romania and Ukraine, whereas Black Sea catchment is situated on the territory of 23 countries. Thus, there is a large spatial gap in data coverage at country scale. This gap is partly covered by available regional and European scale datasets containing data from Danube basin countries, however for the rest of the Black Sea catchment the problem persists.

With respect to the river basins of the Black Sea Catchment:

- The Danube river catchment has the best data coverage. Data are available at all scales: global, European, regional and national;

- The large river basins of Ukraine (Dnieper, Dniester, Bug) seem to have rather acceptable data coverage, 
however due to lack of access to data it is difficult to assess their completeness;

- For the large river basins of Russia (Don, Kuban) and Turkey (Kizilirmak, Yesilirmak) project partners did not report any dataset. This is identified as a significant gap in data, particularly taking into account that these river basins are important for the project end-users and decision-makers: they cover large territories populated by millions of people and have important socioeconomic value for these countries.

The methods of access to data are various: direct Internet links, FTP, e-mail, CD and USB devices. The datasets of country scale are usually not accessible online and have to be requested via e-mail from data holders. The variety of formats for data storage, as well as the absence of online access to the data hamper the data exchange and appear to be a significant gap for the datasets at country scale. Consequently, data accessibility was the main problem for an effective and efficient use of data. Finally, this analysis highlighted the problem of data compatibility while integrating data from different sources and scales. This require users a lot of efforts to make these data compatible before starting to analyze them.

In term of observation systems, satellite-based platforms are the most important. The available observations systems were analyzed regarding their ability to satisfy the project and end-users data requirement. Based on the fact, that all required data types exist in the Black Sea catchment, it can be concluded that respective observation systems, networks and services also exist. The identified gaps in data may result from different factors such as imperfection of respective observation systems, scarcity of monitoring networks, weakness of data exchange mechanisms and services.

However, the results of the gap analysis of the available datasets clearly indicate that in most cases the real problem is the limited or restricted access to data produced by observation systems rather than gaps in observation systems. The relevant problems are also not developed ownership of datasets and lost datasets after projects are completed. With respect to the most problematic data categories identified, they result from the gaps in observation systems, (i.e. the capacity of monitoring networks/services) for (1) pollutants deposition from atmosphere, (2) oceanography (e.g., in situ measurements), (3) sea water quality, and (4) marine biology and biodiversity.

The issue of data accessibility and availability is of primary importance. Even access to the project partners data in many cases is limited or restricted It is recommended to elaborate appropriate data policy, which envisages different types of data access licenses and encourages open data access and exchange for non-commercial purposes. Then projects partners - dataholders have to share their data for the project under the data policy, further encouraging other stakeholders to do the same.

All these gaps reveal the necessity to enable interoperability among project partners' and raise awareness about the benefits of using EO products and services. In particular, this requires building capacities on Earth Observation in the Black Sea catchment through improved data collection, management, storage, analyses and dissemination.

\section{CAPACITY BUILDING BY ENVIROGRIDS}

To enable wide data sharing in the Black Sea catchment, the enviroGRIDS capacity building strategy was articulated around 6 components (fig.1), corresponding to those identified to implement an SDI [7, 25-28]. Following the definition of an SDI, it can be thought as a framework of governance, infrastructures, data, and skills that when associated with funding can achieve geospatial data discovery, access and use.

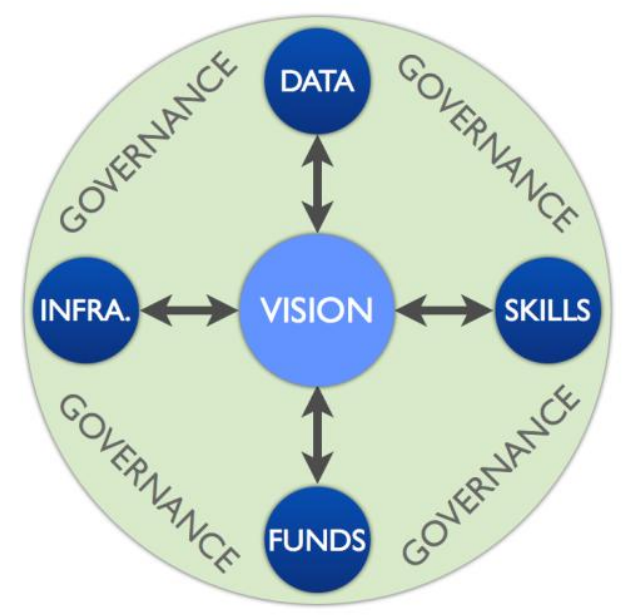

Fig. 1. Components of the enviroGRIDS capacity building strategy.

The central element represents the vision, which should define the objectives that enabling data sharing must target. In the case of enviorGRIDS it was (1) supporting the needs of main end-users (e.g., BSC, ICPDR), (2) facilitating discovery and access to existing data, (3) creating and making available new datasets, (4) contributing to data sharing initiatives like GEOSS and INSPIRE.

To support this vision, funds must be available to have people working on certain number of activities. This will allow developing also the skills of these people through dedicated capacity building activities at the three levels defined by GEO:

- At institutional level, the project has created a network of 30 partners in 15 countries targeting the needs of main end-users: BSC and ICPDR. A gap analysis was completed to give a first overview of the EO capacities in the region. Different factsheets, newsletters and policy briefs were written and translated in regional languages to raise awareness about GEO/GEOSS. International organizations (e.g., UNEP, UNESCO, CERN) were also involved as partners. The project was integrated officially in the work plan of UNEP and GEO. Institutional connections were also enabled with other EU FP7 projects in the region to foster data sharing. Finally, an active collaboration with IEEE and OGC allowed developing and sharing teaching material. EnviroGRIDS also strongly promoted the new membership of countries such as Georgia, Bulgaria and Armenia in GEO, as well as the creation of national GEO nodes. 
- At human level, enviroGRIDS has essentially organized a series of workshops on "Bringing GEOSS into practice 14 to teach policy and decision makers about GEOSS and INSPIRE, to teach technicians how to install required software to share data and metadata using OGC standards, and finally to teach partners how to become the future trainers. This series of workshops was developed to demonstrate the benefits of data sharing and to show the potential of GEOSS. To disseminate as much as possible this content, all the teaching material and courses are available on the enviroGRIDS ${ }^{15}$, GEOSS, and OGC websites. In complement, a Virtual Training Center ${ }^{16}$ was developed for providing various learning resources to the project partners, stakeholders from the Black Sea Catchment involved in environmental management at different levels and anyone who is interested in the research topics covered by enviroGRIDS. A network of scientists working in the region was established through the LinkedIn social network. Finally, an enviroGRIDS channel was created on YouTube ${ }^{17}$ to broadcast several important videos and presentations on the project outputs. For instance, an animation entitled "the Story of Data on the Environment" as well as a documentary prepared by Euronews "Coloring the Black Sea" are clearly promoting data sharing for a more sustainable future.

- At infrastructure level, a distributed grid-enabled spatial data infrastructure shared between several partners of the project was developed to gather, store, discover, access and process key environmental data on the region. Along with the development of the enviroGRIDS SDI, initiatives like GEOSS, INSPIRE or UNSDI were promoted together with the use of OGC and ISO interoperability standards. This enabled partners to develop different tools, build pilot observation systems. In particular, the ICPDR decided to develop its own SDI based on enviroGRIDS recommendations to have more efficient data sharing mechanisms and to improve their environmental assessment processes. Finally, all the components developed in the frame of the project were registered into GEOSS.

As a result of the different capacity building activities we taught more than 300 participants how to share and use data and metadata using OGC and ISO standards, and how to benefit from GEOSS. Based on interoperable services, partners became able to develop different tools to discover, access, process and evaluate data in the Black Sea catchment as well as developing dedicated portals to raise awareness about flooding issues in Romania. All these tools are available in the enviroGRIDS portal ${ }^{18}$ that integrates different components

\footnotetext{
14 http://bit.ly/15H2SVy

15 http://bit.ly/14ThgJe

16 http://bit.ly/JtlEb3

$17 \mathrm{http} / / / \mathrm{www}$. youtube.com/envirogrids

18 http://portal.envirogrids.net
}

supported by different types of infrastructures, enabling communication and data exchange between them.

Additionally, the project created new datasets to explore different scenarios of climate, land cover and demographic changes in the Black Sea catchment, and their impacts on water resources. Several pilot studies were also implemented in different countries on the other GEO Societal Benefit Areas. All the data created by enviroGRIDS is made freely available through web services on the enviroGRIDS portal, where all the available data covering the Black Sea countries are exposed. At the end of the project this has resulted in a set of 27 resources registered into GEOSS (fig.2) corresponding approximately to 300 datasets, giving access to more that 300'000 layers. The effort will continue in different ways. Therefore, this list should increase in the following years.

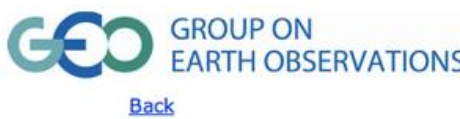

\begin{tabular}{|l|l|}
\multicolumn{1}{c}{ Back } \\
\hline My registration list ( \\
\hline 1 & Black Sea Catchment DEM - WMS \\
\hline 2 & Land Use, Climate, and Demographic Changes Scenarios in the Black Sea Region \\
\hline 3 & - Wand Use, Climate, and Demographic Changes Scenarios in the Black Sea Region \\
\hline 4 & EnviroGRIDS Map toolkit - WMS \\
\hline 5 & EnviroGRIDS.ch metadata catalog - CSW \\
\hline 6 & EnviroGRIDS Hydrological modeling (Wp4) - WMS \\
\hline 7 & ITU GeoServer \\
\hline 8 & Odessa National I.I. Mechnikov University - WMS \\
\hline 9 & Black Sea Commission \\
\hline 10 & SWAT model outputs - WFS \\
\hline 11 & SWAT model inputs - WFS \\
\hline 12 & SWAT model outputs - WMS \\
\hline 13 & Land Use, Climate, and Demographic Changes Scenarios in the Black Sea Region \\
\hline 14 & Taurida National University Geoserver - WMS \\
\hline 15 & EnviroGRIDS URM Portal - Catalog \\
\hline 16 & SWAT model outputs - WCS \\
\hline 17 & SWAT model inputs - WMS \\
\hline 18 & Land Use, Climate, and Demographic Changes Scenarios in the Black Sea Region \\
\hline 19 & Flood Portal Romania - Danube \\
\hline 20 & enviroGRIDS \\
\hline 21 & Basin Scale Hydrological Tool \\
\hline 22 & Grid Based Sattelite Image Processing Platform \\
\hline 23 & Grid Based SWAT Hydrological Models Calibration \\
\hline 25 & GiSHEO elearning Environment \\
\hline 26 & EnviroGRIDS Climate scenarios \\
\hline 27 & enviroGRIDS - Bringing GEOSS services into practice \\
\hline
\end{tabular}

Fig. 2. EnviroGRIDS resources registered in GEOSS.

\section{DISCUSSION/LESSONS LEARNT}

In its 4-year time frame, the enviroGRIDS project members gained some experience and learned some lessons on developing capacities of different user groups.

\section{A. Success stories}

The proposed approach for building capacities in the Black Sea catchment had an impact on several project partners, countries and institutions. Indeed, different partners from Turkey, Ukraine and Romania decided to implement their own 
SDI to share local datasets they are custodians. They all recognize that having participated to the "Bringing GEOSS services into practice" workshops convinced them about necessity to share data and to use interoperable standards. In complement, for the project partners that were not able to develop their own SDI solution, but wanted to make available their data, one of the project partners (e.g., Czech Centre for Science and Society) offered the possibility to publish their data directly on the enviroGRIDS portal.

At the institutional level, the ICPDR, one of the main endusers of the project, found out that data sharing using OGC and ISO standards could bring several benefits for their assessments and reporting processes. They are currently upgrading their system to enable data exchange among the 14 countries covered by the Danube catchment. It will be entirely based on open source software and open standards promoted by enviroGRIDS allowing them to efficiently fulfill the requirements of the INSPIRE directive as well as the Water Framework Directive (WFD).

At the country level, enviroGRIDS was able to raise awareness about GEO/GEOSS. Actually, Georgia and Armenia have contacted the GEO secretariat to become officially new participating members and have already endorsed the GEOSS 10-Year Implementation Plan [29] and its Data Sharing Principles [30]. Bulgaria is also seriously considering its membership to GEO, which would fill the last gap in the countries within the Black Sea catchment.

Finally, the wide adoption among project partners of OGC standards has permitted the development of several components based on different software and computing infrastructures to discover, visualize, access, integrate and analyze environmental data of the Black Sea catchment. In particular, it enabled the communication between geospatial data repositories (e.g., SDIs) and the Grid computing infrastructure to analyze remote sensing high-resolution images and hydrological modeling for the entire catchment (i.e., 2.2 millions square kilometers).

\section{B. Benefits}

At the end of the enviroGRIDS project it is probably too early to highlight major benefits in term of data sharing through GEOSS in the Black Sea Catchment region. However, after 4 years a lot of services were registered facilitating discovery of hundreds of datasets. This can be already considered as a positive result and the number of services and datasets will certainly increase in the forthcoming years.

A relevant impact of GEOSS is the fact that it has enabled networking activities between different contributing projects, creating synergies and fostering information exchange and knowledge development. Moreover, it has also permitted different scientific communities to come together and start talking to each other. In particular, participating to GEOSS allows taking part to activities like Architecture Implementation Pilots (AIP) and other meetings that stimulate and coordinate efforts like efficient data sharing, models integration, user engagement, or capacity building.

Lastly, the use of Free and Open Source Software (FOSS) was truly beneficial in term of capacity building and implementation of data sharing solutions. They are especially attractive for students, GIS professionals, small and medium enterprises, companies and institutions in emerging countries and international organizations. The zero-license cost is obviously an advantage but more important the promoted solutions (e.g., GeoServer, GeoNetwork, PostGIS, OpenLayers, PyWPS, THREDDS) have proven to be efficient [31]. Additionally the fact that all the teaching material including software can be freely disseminated allowed trainees to become trainers.

This contributes to lower entry barriers for both resource users and providers, facilitate development of technical skillsand empower local people.

\section{Limitations}

Several obstacles were encountered while trying to promote data sharing in the Black Sea catchment. Besides technological aspects main issues identified are related to (1) political/cultural context, (2) policies, (3), organization, (4) people and (5) resources. Same issues were also reported by different authors in various assessments and consultations in Europe [32-38].

The main obstacle faced during the project was the lack of institutional and political wills to publish and share. Indeed, data providers tend to hide data mostly for confidentiality, national security or "misuse prevention" reasons. Additionally, lack of awareness and insufficient staff skills induce shortcomings in standardization (e.g., data, metadata, procedures) and documentation. This results in an incoherent, inconsistent and unshared vision and creates (1) difficulties in finding/accessing dataand (2) lack of knowledge from data providers about the value of what they have.

\section{Recommendations}

Based on the experience acquired, the success stories and both benefits and limitations encountered, several recommendations can be formulated for data providers and data users for (1) continuing and improving the development of capacities in the region and (2) raising awareness about the benefits of sharing data. For data providers we recommend:

- Asking the UN, EU and national institutions to show the example by making all their data available.

- Improving the GEOSS and INSPIRE geoportal interface to transform the experience of data searching into something more efficient.

- Enhancing data policies to facilitate provision and publication of data. For Arzberger et al. [39] publicly funded data are a public good, produced in the public interest and thus should be freely available to the maximum extent possible. Ideally this should be a guiding principle for every institution.

- Strengthening the sustainability of observation systems especially if capacities are developed in the frame of projects financed for a dedicated period. Memorandums of Understanding (MoUs) can be useful means to ensure the maintenance of essential components of an infrastructure. 
- Raising financial resources and engage donors in capacity building activities. To reach this objective it should be demonstrated that EO products and services could offer social and economic impacts. Some reports are already highlighting positive financial impacts and associated costs of non-actions [32, 40-42]. The coordinated approach of GEO should facilitate the engagement of donors by matching identified development needs and their priorities and by developing networks of donors [19].

- Enlarging EO network should be also a priority. It is recognized by GEO as an cost-effective mean of coordination for capacity building efforts [19]. It facilitates exchange of ideas and best practices, creates opportunities of collaboration, encourage exchange for training purposes, promote an open and sharing spirit. Encouraging people and institutions to participate to GEO events like the GEO European Projects Workshop or the GEO \& OGC AIP activities are good opportunities to collaborate and exchange with others. Moreover web 2.0 technologies and e-learning platforms were coined as promising solutions in developing capacity building networks [43-45].

- Keeping it simple and let users experience the benefits of interoperability.

- Making the data services directly discoverable by web browser, while reconnecting the metadata with the data itself with a unique identifier for each dataset.

- Developing network of sensors and means to acquire new data, particularly time-series, on identified data gaps.

- Moving away from data formats suitable for 2 dimensions towards multidimensional formats such as NetCDF [46].

- Developing further transparent solutions for large data sharing and processing on distributed computing solutions.

- Developing local/regional node to support GEO. This can help to leverage human, technical and institutional capacities and knowledge.

- Keeping some independence from dedicated solution. Making data available with interoperable services will allow disseminating data to the maximum extent possible and ensuring participating to different initiatives.

- Sharing and documenting data is part of the elementary scientific approach, enhancing scientific accountability and credibility.

- Publishing data and making them discoverable using interoperable standards. There are a lot of different endusers communities that are willing to use EO products and services and that may add value to those products and services.
- Encouraging scientists to share their datasets by allowing them to publish a short description of their datasets on a referenced journal like traditional articles.

- Improving automatic data and services quality checking on all geoportals.

- Developing tailored tools to match the requirements and needs of end-users. If they perceive a benefit then it will facilitate reaching commitments and endorsements. In particular, dedicated thematic and regional portals can be beneficial.

- For end users, we recommend:

- Participating in events of targeted end-users. This facilitates exchange, discussions and ensures that the capacity building activities are answering a specific need of end-users. This is also an opportunity to raise awareness about the benefits of data sharing initiatives like GEOSS and to understand what are the needs of end-users.

- Promoting the use of open source software and the development of freely available education and teaching material. This will help to reach and disseminate resources to the widest audience possible. Additionally, this will ensure a sustainable technology transfer by making accessible cost effective and end-user friendly solutions.

- Promoting regional and thematic geoportals that can more easily implement added values to the shared data.

- Investing in massive learning solutions (Massive Open Online Courses - MOOC) to better promote data sharing needs and solutions among all potential end users.

- Enhancing an "open and sharing spirit" through participative approach. Capacity building activities should demonstrate the benefits of data sharing through appropriate examples communicate best practices and develop guidelines and policies. Altogether this will help to reach agreement and endorsement on the use of new standards.

- Getting involved early in the decision processes and discussions of targeted end users in order to favor the uptake of the promoted solutions.

- Enabling institutions and people to work together and share a common vision.

All these recommendations are aiming to positively influence both data providers and end-users to endorse standards and to commit to data sharing. However, it remains that currently SDI concepts and methods are still strongly related to the geospatial community. In our view, it is required establishing interdisciplinary networks to cross-fertilize disciplines and to promote integration. GEO/GEOSS and INSPIRE represent promising arenas to face this challenge.

Capacity building is a key element to gain acceptance and adoption about data sharing [22]. However, it is a long-term process and the best solution is to establish a long-term 
commitment to education and research [47]. Like in any new technologies, the old generations are often more reluctant to adopt them, while often still occupying the positions where decisions are taken.

To improve support and commitment to data sharing, Rajabifard et al. propose [26]: (1) increasing the level of awareness about the nature and value of EO products and services (e.g., capacity building), (2) assessing and understanding the dynamic nature of collaboration and partnership in order to sustain a culture of sharing, (3) improve SDI models to better match the needs of various communities, (4) improve SDI definition to give a clearer vision of its potential benefits and (5) identifying the key factors (in a given context) that can facilitate interactions between social, economical and political issues.

\section{CONClusions}

Without sharing data: (1) doing science can be difficult, (2) taking sound decisions can be problematic and (3) envisioning a sustainable development can be complicated. There are a lot of enablers that can influence data sharing. From a technological point of view, all the building blocks are available but the most important component to reach endorsement is not technology but it relies on people (e.g., collaboration, cooperation, social relation, willingness to share and to learn). Indeed, developing the technological component is rather simple but building and maintaining the social one is much more difficult requiring important human and financial resources as well as collaboration, partnership, commitment and trust. Consequently, SDIs can be thought of as social networks of people and organizations supported by data and technology [48].

The answers to the three initial questions can be found below:

1) The Black Sea catchment clearly needs improved EO solutions, like any region of the world, because this catchment represents a federating transboundary unit that is feeding with water the most emblematic geographic feature of the region, the Black Sea itself. Only a well-organized EO system will allow for the important institutions such as the ICPDR and the BSC to address the complex environmental issues influencing water resource sustainability and its vulnerability towards global changes in climate, land cover and demography.

2) The scientists, especially the younger ones, are ready to implement largely the directives and principles of the data sharing promoted by INSPIRE and GEO. From an institutional point of view, there are still too many barriers to encourage a change in paradigm around the true value of EO data. The potential direct commercial value is still dominating the decisions, slowing down significantly the development of an entire economical sector dedicated to geospatial services. The adoption of the INSPIRE directive in European countries and beyond, certainly represent a very promising prospect. From an infrastructure perspective, the main problem resides in the costs for maintaining and developing proper EO systems combining remote sensing with networks of field stations and sensors. Then, the data sharing solutions are becoming really easy to implement with efficient open source and commercial solutions. Data sharing and distributed geoprocessing solutions are largely dependent on fast and reliable Internet infrastructures. The dissemination of EO will become more and more oriented towards mobile devices that are themselves dependent on good cell phone and Wi-Fi coverages.

3) We gave above a long list of recommendations to improve EO in the Black Sea region for data providers and users. These recommendations will only be transformed into actions if there is a strong political understanding and support that data sharing of EO data is essential for guiding the region into a more sustainable future. In a time of important financial and economical difficulties, the very reasonable additional cost of making existing or newly collected data available should be perceived as a high-return strategy for the society.

\section{ACKNOWLEDGMENT}

The authors would like to acknowledge the European Commission "Seventh Framework Program" that funded the enviroGRIDS project (Grant Agreement no. 227640).

The views expressed in the paper are those of the authors and do not necessarily reflect the views of the institutions they belong to.

\section{REFERENCES}

[1] Stanners, D.A. and P. Bourdeau, Europe's environment: The Dobrisassessment, E.E. Agency, Editor 1995, European Environment Agency: Copenhagen.

[2] Mancuso, E., et al., Future land use change scenarios for Black Sea Bastin.

[3] Gerlak, A.K., J. Lautze, and M. Giordano, Water resources data and information exchange in transboundary water treaties. International Environmental Agreements-Politics Law and Economics, 2011. 11(2): p. 179-199.

[4] Roehring, J., Information Interoperability for River Basin Management, in Technology Resource Management and Development2002. p. 127134.

[5] Gore, A., The Digital Earth: Understanding our planet in the 21st Century, 1998. p. 4.

[6] Lecca, G., et al., Grid computing technology for hydrological applications. Journal of Hydrology, 2011. 403(1-2): p. 186-199.

[7] Nebert, D.D., Developing Spatial Data Infrastructure: The SDI Cookbook2005. 171.

[8] Ames, D.P., et al., Introducing the Open Source CUAHSI Hydrologic Information System Desktop Application (HIS Desktop). 18th World Imacs Congress and Modsim09 International Congress on Modelling and Simulation, 2009: p. 4353-4359.

[9] Open Geospatial Consortium, The Havoc of Non-Interoperability, 2004. p. 7.

[10] Open Geospatial Consortium, Geospatial Portal Reference Architecture, 2004. p. 23.

[11] Open Geospatial Consortium, OGC Reference Model, 2008. p. 35.

[12] Open Geospatial Consortium, OGC Market Report: Open Standards and INSPIRE, 2012. p. 32.

[13] Open Geospatial Consortium, The Importance of Going “Open”, 2005.

[14] Giuliani, G., N. Ray, and A. Lehmann, Grid-enabled Spatial Data Infrastructure for environmental sciences: Challenges and opportunities. Future Generation Computer Systems, 2011. 27(3): p. 292-303.

[15] Ray, N., et al., Distributed Geocomputation for Modeling the Hydrology of the Black Sea Watershed, in Environmental Security in Watersheds: The Sea of Azov, V. Lagutov, Editor 2012, Springer. p. 141-157. 
(IJACSA) International Journal of Advanced Computer Science and Applications, EnviroGRIDS Special Issue on "Building a Regional Observation System in the Black Sea Catchment"

[16] European Commission, Priorities for a new strategy for European Information Society, 2010.

[17] GEO secretariat, Building a Global Earth Observation System of Systems, 2008. p. 7.

[18] GEO secretariat, Global Earth Observation System of Systems 10-Year Implementation Plan Reference Document, 2005. p. 209.

[19] GEO secretariat, GEO Capacity building strategy, 2006. p. 13.

[20] Noort, M., GeoNetCab: Marketing Earth Observation Products and Services, Part \#2, 2013.

[21] Noort, M., The GEONetCab approach to Capacitiy Building, 2012.

[22] Rajabifard, A. and I.P. Williamson. SDI Development and Capacity Building. in GSDI-7. 2004. Bangalore, India.

[23] Williamson, I.P., A. Rajabifard, and S. Enemark, Capacity Building for SDIs, in 16th United Nations Regional Cartographic2003: Okinawa, Japan. p. 1-14.

[24] Arnold, J., et al., Large area hydrologic modeling and assessment - Part 1: Model development. Water resources bulletin, 1998. 34(1): p. 73-89.

[25] Craglia, M. and A. Annoni, Building a Spatial Data Infrastructure for Europe: the many research questions for which we need answers, in GISRUK2007: NUI Maynooth, Ireland. p. 1.

[26] Rajabifard, A., M.-E. Feeney, and I. Williamson, The Cultural Aspects of Sharing and Dynamic Partnerships within an SDI Hierarchy. Cartography Journal, 2002. 31(1).

[27] Rajabifard, A. and I.P. Williamson. Spatial Data Infrastructures: Concept, SDI Hierarchy and Future directions. in Geomatics'80. 2001. Tehran, Iran.

[28] Williamson, I., A. Rajabifard, and A. Binns, Challenges and Issues for SDI development. International Journal of Spatial Data Infrastructures Research, 2006. 1: p. 24-35.

[29] GEO secretariat, The Global Earth Observation System of Systems (GEOSS) 10-Year Implementation Plan, 2005. p. 11.

[30] GEO secretariat, White Paper on the GEOSS Data Sharing Principles, 2008. p. 93.

[31] Giuliani, G., A. Dubois, and P. Lacroix, OGC Web Feature and Coverage Services performance testing: towards an efficient delivery of geospatial data. Journal of Spatial Information Science, 2013.

[32] Craglia, M. and M. Campagna, Advanced Regional Spatial Data Infrastructures in Europe, in JRC Scientific and Technical Reports2009. p. 132.

[33] Bregt, A.K., et al., Changing demands for Spatial Data Infrastructure assessment: experience from The Netherlands, in A Multi-View Framework to Assess Spatial Data Infrastructures2008. p. 357-369.

[34] Eelderink, L., J. Crompvoets, and W.H. Erik De Man, Towards key variables to assess National Spatial Data Infastructures (NSDIs) in developing countries, in A Multi-View Framework to Assess Spatial Data Infrastructures2008. p. 307-325.

[35] Giff, G., et al., Geoportals in Selected European States: A NonTechnical Comparative Analysis. International Journal of Spatial Data Infrastructures Research, 2008.

[36] Grus, L., J. Crompvoets, and A.K. Bregt, Multi-view SDI Assessment Framework. International Journal of Spatial Data Infrastructures Research, 2007. 2: p. 33-53.

[37] Henricksen, B., UNSDI Compendium: A UNSDI Vision, Implementation Strategy, and Reference Architecture, 2007, UNGIWG. p. 150 .

[38] Vandenbroucke, D., Spatial Data Infrastructures in Europe: State of play sptring 2010, 2010. p. 1-72.

[39] Arzberger, P., et al., Promoting Access to Public Research Data for Scientific, Economic and Social Development. Data Science Journal, 2004. 3: p. 17.

[40] Booz, Allen, and Hamilton, Geospatial Interoperability Return on Investment, 2005, NASA. p. 47.

[41] European Commission, Assessing the impacts of Spatial Data Infrastrucutres, J.R. Center, Editor 2006: Ispra. p. 1-61.

[42] Garcia Almirall, P., M. Moix Bergada, and P. Queralto Ros, The SocioEconomic impact of the Spatial Data Infrastructure of Catalonia, M. Craglia, Editor 2008. p. 62.

[43] Alvarez, M., T. Delgado Fernandez, and R. Cruz Iglesias, Social networks and Web 2.0 tools as a good complement to the local SDI's, in GSDI-122010: Singapore. p. 1-14.

[44] Alvarez, M. and D. Gallego Gil, Training in Web 2.0 tools: a way to bring Spatial Data Infrastructures to people, in GSDI-122010: Singapore. p. 1-10.

[45] Gonzalez, M.E. and M.A. Bernabe, E-learning training for Spanish Compulsory Secondary Education Teachers to Use SDI as an ICT Educational Resource, in GSDI-122010: Singapore. p. 1-15.

[46] Signell, R.P., et al., Collaboration tools and techniques for large model datasets. Journal of Marine Systems, 2008. 69(1, Äì2): p. 154-161.

[47] Gonzalez, M.E., Spatial Data Infrastructures as an Educational Resource in Secondary Education in Spain and Argentina. International Journal of Spatial Data Infrastructures Research, 2008.

[48] Craglia, M. and M. Campagna, Advanced Regional SDIs in Europe: comparative cost-benefit evaluation and impact assessment perspectives. International Journal of Spatial Data Infrastructures Research, 2009. 